\title{
Considerações sobre a aula de art repensando saberes e fazeres
}

\author{
Art class considerations: r \\ knowledge and doing \\ Consideraciones de la lecci \\ repensar el conocimiento y
}

Carminda Mendes André 1 Maiquel Cristian Reichert

1 Pesquisadora doutora e docente do Programa de Pósde Artes da Universidade Estadual Paulista - UNESP. Coorc Performatividades e Pedagogias CNPq. CV: http://latt E-mail: mendes.andre@unesp.br.

2 Professor de Arte - PEB II, ensino público em São Bern do Programa de Pós-Graduação em Arte do Instituto de cnpq.br/2991238991320068; ORCID: https://orcid.org/ cristian.reichert@unesp.br. 


\section{RESUMO}

Propomos neste artigo, refletir sobre aspectos importantes da aula de Arte em contexto educacional formal ou não-formal - nosso foco não se encontra na relação com as instituições mas com a questão epistemológica do fazer docente. Para começar propomos a diferenciação entre criatividade e invenção, aspectos políticos de ambos os conceitos e porque para nós inventar é um ato de emancipação dos sujeitos e criar, no sentido amplamente usado na educação, se configura um conceito cooptado por uma ideia mercadológica de educação. Analisamos a aula de Arte e sua relação com a ideia de arte relacional, ou participativa como preferimos. Por fim, pensamos nas contribuições que a arte pode oferecer à educação e seus modos de fazer, para isso visionamos uma educação, no sentido amplo, pelo paradigma artístico e buscamos entender os fundamentos da educação pelo paradigma científico em voga, o das ciências cognitivas.

\section{PALAVRAS-CHAVE}

Aula de Arte; criatividade; invenção; aula participativa; arte educação

\section{ABSTRACT}

In this article we propose to reflect on important aspects of the Art class in a formal or non-formal educational context - our focus is not on the relationship with institutions but with the epistemological issue of teaching. To begin with, we propose the differentiation between creativity and invention, political aspects of both concepts and because for us inventing is an act of emancipation of the subjects and creating, in the sense widely used in education, a concept co-opted by a market idea of education is configured. We analyzed the Art class and its relationship with the idea of relational or participatory art as we prefer. Finally, we think about the contributions that art can offer to education and its ways of doing, for that we envision education, in the broad sense, by the artistic paradigm and we seek to understand the fundamentals of education through the current scientific paradigm, that of the cognitive sciences.

\section{KEY WORDS}

Art class; Creativity; Invention; Participatory Classes; Art education

\section{RESUMEN}

En este artículo nos proponemos reflexionar sobre aspectos importantes de la clase de Arte en un contexto educativo formal o no formal, nuestro enfoque no está en la relación con las instituciones sino en el tema epistemológico de la enseñanza. Para empezar, proponemos la diferenciación entre creatividad e invención, aspectos políticos de ambos conceptos y porque para nosotros inventar es un acto de emancipación de los sujetos y crear, en el sentido ampliamente utilizado en educación, un concepto cooptado por un mercado. Se configura la idea de educación. Analizamos la clase de Arte y su relación con la idea de arte relacional o participativo como prefiramos. Finalmente, pensamos en los aportes que el arte puede ofrecer a la educación y sus formas de hacer, para ello vislumbramos la educación, en sentido amplio, desde el paradigma artístico y buscamos comprender los fundamentos de la educación a través del paradigma científico actual, que de las ciencias cognitivas.

\section{PALABRAS CLAVE}

Clase de arte; Creatividad; Invención; clases participativas; educación artística 


\section{Introdução: antes de tudo, criar ou inventar?}

Ao distinguirmos criatividade e invenção, buscamos refletir sobre uma importante prerrogativa da aula de Arte: a produção - mobilizando a imaginação na prática artística, considerando-a como espaço para a livre expressão e elaboração crítico estética do mundo. No campo dos conceitos, criatividade e invenção, estão próximos, mas é necessário distinguir alguns pontos para termos consciência da práxis arte educadora. Entendemos que o tipo criativo, na acepção da indústria criativa ${ }^{1}$, tem como ação elaborar e solucionar problemas promovendo o máximo rendimento por meio de um corpo imaginativo, como Pascal Gielen (2015) brinca "lucriatividade dominante". Esta questão é importante por denunciar como a ideia de criatividade foi cooptada pelo modelo capitalista - onde o tipo criativo é possuidor de uma qualidade profissional do sujeito bom para o mercado - e pela política. Já o tipo inventivo atua no campo da necessidade por autonomia política e empoderamento (ANDRÉ, 2011), uma necessidade de existir e resistir perante o massacre cultural promovido pela cultura de massa, nesse sentido, De Certeau (1998) percebe a invenção como uma tática de subversão que cria pequenas fissuras de existência no âmbito da cultura de massa.

No campo da educação, as teorias sobre criatividade têm sido amplamente debatidas a partir da segunda metade do século $X X$ pelos teóricos da psicologia cognitiva - principalmente nos EUA, devido à corrida espacial e à Guerra Fria. Tal impulso buscava alavancar o poderio americano por meio de políticas educacionais que visassem descobrir novos, e precoces, talentos, por meio de testes e mecanismos de detecção de superdotação nas escolas, que possuíam como base os estudos sobre criatividade (FLEITH, 2001). Dentre os principais teóricos, alguns estão ligados ao campo da psicologia cognitiva e outros ao movimento humanista (críticos ao sistema educacional que buscava transformar a escola num lugar de "treinamento criativo")(FLEITH, 2001). O maior expoente foi o professor Joseph Renzulli (1992) que elaborou uma metodologia de produção criativa na escola, o chamado Modelo de Produtividade Criativa, onde a "aprendizagem não pode ser analisada apenas do ponto de vista do comportamento, mas deve ser compreendida como resultado da interação de três fatores: o aprendiz, o professor e o currículo escolar" (FLEITH, 2001, p. 57). Neste modelo, Renzulli (1992) propõe que o estudante seja encorajado a produzir conhecimento e não apenas assimilar. Podemos inferir, então, que a ideia de criatividade aplicada à educação fez parte de uma política de estado de defesa e dominação geopolítica, pela óbvia importância do fator humano em sustentar tais políticas.

Na arte educação esta lógica se apresenta na forma de produção de soluções criativas, serve ao design, à publicidade, aos processos de sensibilização e instrumentalização estética - e não nas experiências insurgentes. Para esta lógica a

1 Indústria criativa é um termo usado por Pascal Gielen em seu livro "Criatividade e outros fundamentalismos", este termo surge da ideia de indústria cultural introduzido por Adorno e Horkheimer nos anos 40 (GIELEN, 2015). 
arte educação tem utilidade na instrumentalização de agentes capazes de sanar crises pontuais com soluções criativas (ANDRÉ, 2011). Gielen denuncia o esvaziamento da noção de criatividade na atualidade:

A palavra mágica nos dias de hoje é criatividade. E não somente para artistas: gestores e políticos também demandam criatividade. Até mesmo terapeutas familiares e mediadores de conflito insistem para buscarmos mais soluções criativas. Hoje em dia, a criatividade é totalmente relacionada à moralidade positiva. Nós esperamos somente coisas boas dela. Mas o que permanece do significado desta palavra quando todos a estão usando à exaustão? E de onde vem esse desejo? Ele não seria, pelo contrário, um sinal da perda gradual da verdadeira criatividade? (GIELEN, 2015, p. 07).

Percebemos que quando o modelo capitalista se apropria da ideia de criatividade, o faz com o intuito de pautar formas de ações subversivas ou fora do padrão no ambiente corporativo, ou até artísticas. Uma ação de capitalismo humanizado que "permite" o desenvolvimento imaginativo de seus colaboradores, que "permite" um ambiente corporativo descontraído e "descolado" como um ateliê de arte. Esses modelos aparecem como modus operandi das relações de trabalho nas Big Techs (Google, Facebook...) e nas startups, na forma de ambientes estimulantes, inovadores e criativos.

No oposto disso, invenção assume, para nós, uma perspectiva foucaultiana, para quem o conhecimento é uma construção, uma invenção humana não instintiva. Michel Foucault (2002, p. 15) faz uma leitura da obra de Nietzsche - Sobre a verdade e mentira no sentido extramoral ${ }^{2}$ (2007) - para chegar a esse entendimento: "A invenção - Erfindung - para Nietzsche é, por um lado, uma ruptura, por outro, algo que possui um pequeno começo, baixo, mesquinho, inconfessável. Este é o ponto crucial da Erfindung". Inventa-se por necessidade de se posicionar frente ao mundo, ressignificando-o, ou inicializando-o. Foucault em A verdade e as formas jurídicas (2002), vai além:

O conhecimento foi, portanto, inventado. Dizer que ele foi inventado é dizer que ele não tem origem. É dizer, de maneira mais precisa, por mais paradoxal que seja, que o conhecimento não está em absoluto inscrito na natureza humana. O conhecimento não constitui o mais antigo instinto do homem, ou, inversamente, não há no comportamento humano, no apetite humano, no instinto humano, algo como um germe do conhecimento. De fato, diz Nietzsche, o conhecimento tem relação com os instintos, mas não pode estar presente neles, nem mesmo por ser um instinto entre os outros; o conhecimento é simplesmente o resultado do jogo, do afrontamento, da junção, da luta e do compromisso entre os instintos.

É porque os instintos se encontram, se batem e chegam, finalmente, ao

2 "Em algum remoto recanto do universo, que se deságua fulgurantemente em inumeráveis sistemas solares, havia uma vez um astro, no qual animais astuciosos inventaram o conhecimento. Foi o minuto mais audacioso e hipócrita da "história universal": mas, no fim das contas, foi apenas um minuto" (NIETZSCHE, 2007, p. 25). 
término de suas batalhas, a um compromisso, que algo se produz. Este algo é o conhecimento. (FOUCAULT, 2002, p. 16)

O conhecimento como construção está conectado ao poder e por isso a invenção é um ato político. Com invenção propomos formas de experimentar a vida, inventando sentidos que subvertam a ordem cotidiana e alterando percepções cristalizadas pelo automatismo da cultura de massa.

Ao contrário do tipo criativo, cooptado, este não se propõe a atingir metas, dar resultados, mas sim se constituir enquanto tática pedagógica, como quer De Certeau, no campo das necessidades (ANDRÉ, 2011). Temos então uma possibilidade artística porosa e não endurecida, que se alimenta, inclusive das impossibilidades, para se fazer presença. Algo que a muito tempo as culturas populares, e em especial as culturas indígenas, souberam explorar como tática de resistência e existência cultural diante das operações de apagamento. Michel De Certeau em seu livro A invenção do Cotidiano (1998) afirma que diversas culturas e povos aprenderam a subverter os dispositivos de controle através de táticas que se fazem no pequeno, no minucioso do cotidiano, e assim escapam aos mecanismos disciplinares:

[...] por traz dos bastidores, tecnologias mudas determinam ou curtocircuitam as encenações institucionais. Se é verdade que por toda a parte se estende e se precisa a rede de "vigilância", mais urgente ainda é descobrir como é que uma sociedade inteira não se reduz a ela: que procedimentos populares (também "minúsculos" e cotidianos) jogam com os mecanismos da disciplina e não se conformam com elas a não ser para alterá-los; enfim, que "maneiras de fazer" formam a contrapartida, dos lados dos consumidores ("ou dominados"?) dos processos mudos que organizam a ordenação sóciopolítica (DE CERTAU, 1998, p. 41).

Também o arte educador inventivo dentro das instituições culturais ou educacionais, aprendeu a resistir como aponta De Certau, criando para si uma tática pedagógica que se faz nas beiradas, nas frestas, como os povos originários resistem sem se fragilizar, sem criar grandes ações subversivas que o denunciem, mas se fazendo na "pequena ação potente". Da mesma forma o professor de arte, propõe na pequena ação subversiva, formas de agir no contexto cultural das instituições escolares ressignificando sujeitos e ambientes, promovendo "um ensino que recoloque a escola como um lugar de transformação" (ANDRÉ, 2011, p. 28). E quando reiteramos a ideia de "ação minúscula", "pequena ação", estamos pensando no sujeito que precisa resistir num ambiente ordenado sócio politicamente sem se expor demasiado, munindo-se contra a fragilidade da exposição que o transforma em alvo. 


\section{Pensar numa aula de Arte participativa ${ }^{3}$}

Para desenvolvermos a compreensão de uma aula de Arte participativa pensando em arte participativa; devemos ter a dimensão sobre a produção de arte na pós modernidade: da ideia de obra à ideia de objeto. A ideia de obra é bem definida na história da arte e remonta aos ideais românticos das belas artes: o belo, o harmônico, o equilibrado; algo que remete à pintura como expressão máxima de arte. Neste contexto a obra de arte pretende ser a obra prima. Esta é uma definição aceitável por um longo período. Celso Favaretto (1999) afirma que a arte na pósmodernidade não reivindica mais a ideia de obra, mas sim a de objeto. As obras de artes saltam para o espaço e ganham tridimensionalidade. A própria ideia de pintura se articula à ideia de objeto ${ }^{4}$. Precisamos ponderar que também a ideia de objeto se associa à ideia de design, e não estamos tratando deste tipo de objeto funcional, mas sim, no objeto capaz de gerar situações, criar tensões, o objeto propositor (MARTINS,2005). Nesse sentido Favareto (1999) concebe o papel do artista como o de propositor de situações para que o "ex-espectador" (agora participante) possa interferir junto com ele na reconfiguração da obra/objeto, ambos vão fazer parte da obra de arte participativa. Em sentido aproximado, contempla-nos as ideias de plano de imanência ${ }^{5}$ e jogos de tensões, pois provocam a percepção de que a obra é um campo de atravessamentos - assim percebemos a aula de Arte. Virgínia Kastrup nos aproxima dessa ideia:

Uma obra que não deve ser tomada como um objeto, mas como um conjunto de forças, forças que vão atravessar aquele que dela consegue se aproximar. Entrar em contato é se deixar atravessar por essas forças que nela circulam (KASTRUP, 2007, p. 42).

A autora coloca a obra de arte no campo das experiências, e que para se entrar em contato é preciso ter uma atitude aberta e disponível para o atravessamento, para assim ocorrer o encontro. Já Imanol Aguirre (2009, p. 162) diz: "aproximemos da obra de arte, não como um texto cifrado [...] mas como um condensado de experiência gerador de uma infinidade de interpretações, o valor da arte não está nos artefatos em si, mas na atividade experienciada". Desta forma também entendemos a aula de Arte: como um campo de forças que possibilitem o encontro e a experiência. Como afirma John Dewey em Arte como experiência (2010):

\footnotetext{
3 Quando falamos em "aula de Arte" não queremos analisar um espaço (formal, não formal), mas sim uma prática que perpasse por diversos espaços de atuação do arte educador.

4 Celso Favaretto, no vídeo "É isso arte?" (1999), aponta que o conceito de obra de arte, tão indistintamente usado para se referir à arte, de forma geral, não consegue mais "dar conta" das transformações artística do século XX pós anos 60, pois o conceito obra de arte neste período não está mais associado ao belo e harmônico, sendo muitas vezes horrível e grotesco, já o conceito objeto possibilita deslocar ideais estéticos onde a categoria do feio passa a ser tão importante quanto a categoria do belo. "Um belo horrível".

5 O plano de imanência é a gigantesca nuvem de gás que gera novas estrelas na galáxia dos conceitos! O plano de imanência é o campo fértil onde a vida quer crescer, um berçário de ideias. Contornos variáveis inscritos sobre o plano, operando um corte no caos, o plano de imanência faz apelo a uma criação de conceitos. Deleuze \& Guattari, O que é a Filosofia? (1992)
} 
Temos uma experiência singular quando o material vivenciado faz o percurso até sua consecução. Então, e só então, ela é integrada e demarcada no fluxo geral da experiência proveniente de outras experiências. Conclui-se uma obra de modo satisfatório; um problema recebe sua solução; um jogo é praticado até o fim [...] conclui-se de tal modo que seu encerramento é uma consumação, e não uma cessação. Essa experiência é um todo e carrega em si seu caráter individualizador e sua autossuficiência. Trata-se de uma experiência. (DEWEY, 2010, p. 110)

Por esse caminho, o encontro, a experiência e o contato, por mais que sejam conceitos distintos, ganham contornos parecidos, os quais podemos relacionar com um experimento integral de caráter estético "que permite perceber sua estrutura, independente de se relacionar com objetos artísticos ou não" (MARTINS; DEMARCHI, 2016, p. 04).

A aula de Arte como entendemos, e como almejamos, se direciona para a experiência estética de encontro entre corpos sensíveis, na construção de novos afetos e novas percepções. Assim podemos expandir e pensar procedimentos para reinventar uma educação mais humana e menos bancária.

\title{
O que pode a arte na educação?
}

Ao pensar na arte em ambientes escolarizados, percebemos que os modos de fazer da prática artística muitas vezes é incompreensível para gestores e equipe escolar, acostumados ao modelo de educação tecnicista em detrimento do aspecto humano e poético de educar. Mas de onde surge essa ideia da educação como uma ciência de resultados e submissa ao preceito da qualidade total? Devemos voltar ao lluminismo:

\begin{abstract}
O movimento de Galileu dá atenção para o qualitativo, para um foco na quantificação de relações, não foi tal como Dewey aponta, apenas uma modificação no método; foi uma revolução conceitual. Ele representou uma mudança fundamental na maneira como o mundo era visto e representado. De acordo com o filósofo e historiador de ciência Stephen Toulmin, a mudança foi da atenção do temporal para a atenção do intemporal, de uma ênfase no oral para uma ênfase no escrito, da atenção do particular para a busca do universal (EISNER, 2008, p. 08).
\end{abstract}

As artes, enquanto possibilidade de dar uma nova dimensão do processo educacional, mais melhorado, mais humano, é considerada um "retroceder [...] algo a que se recorre quando não há ciência para fornecer direção" (Eisner,2008, p. 06). 0 caminho continua sendo o da ciência (ciência cartesiana) que possa dar credibilidade com seus métodos, com seus processos de avaliação segura, o que as artes não têm a menor pretensão de fazer. Eliot Eisner (2008), em seu artigo "O que pode a educação aprender das artes sobre a prática da educação?" assegura que na falta da ciência a 
arte é uma posição de retorno:

A influência da psicologia na educação teve outra queda. No processo, a ciência e a arte tornaram-se estranhas. A ciência era considerada confiável, o processo artístico não era. A ciência era cognitiva, as artes eram emocionais. A ciência era ensinável, as artes exigiam talento. A ciência era testável, as artes eram questões de preferência. A ciência era útil e as artes eram ornamentais. Ficou claro para muitos então, como é hoje para muitos, que lado da moeda importava. Como afirmei, dependia-se da arte quando não havia ciência para fornecer orientação. Arte era uma posição de retorno. (EISNER, 2008, p. 07).

Compreende-se que diante do paradigma científico, a educação perca seu caráter poético, a generosidade que envolve o ato de ensinar é completamente relegada, não que a educação tivesse tido esse lugar nos períodos obscuros da história, mas podemos ter outra leitura quando levarmos em conta o processo de formação na Grécia antiga, por exemplo, com o advento da Paideia ${ }^{6}$ e a formação do cidadão. Algo muito próximo a uma educação poética, claro, guardando as devidas proporções e os devidos aspectos culturais ${ }^{7}$.

Mas em nosso contexto o paradigma científico se mostrou mais capaz de objetivar a educação, ou otimizar os estudantes.

Tradicionalmente, e especialmente desde o início da década de 1950, os métodos de investigação educacional têm sido geralmente baseados empiricamente e "cientificamente" orientados. Eles frequentemente tentaram gerar dados que poderiam ser transferidos para um formato facilmente acessível e quantificável. Além disso, a pesquisa dominante foi escrita em um estilo que não permite interpretações artísticas nem o uso de linguagem interpretativa literária. Termos como "sistemas de entrega de conhecimento", "estratégias de avaliação", "tutoria e avaliação de pares", "esquemas de crescimento", "aprendizado baseado na descoberta" e "ciclo de seis dias" fomentam a ideia de ensino técnico e científico. No entanto, se o ensino é visto e estudado sob uma perspectiva comportamental, sociológica, psicológica ou antropológica, nosso entendimento frequentemente parece incompleto ou insatisfatório Expressões qualitativas do ato de ensinar e sua dinâmica interna têm sido muitas vezes perdidas, negligenciadas, ignoradas ou desconsideradas, possivelmente porque não são facilmente quantificadas ou articuladas. (BARREL, 1991, p. 333)(TRADUÇÃO NOSSA)

\footnotetext{
6 A Paideia é a formação geral que dará a cada homem a sua forma humana, ou seja, que o construirá como homem e cidadão. Este ideal de Paideia aparece claramente no séc. IV a. C. e encontra-se bem presente em Sócrates, em Platão, em Aristóteles ou em Isócrates. A finalidade de tal programa educativo era desenvolver a sofrosyne, que podemos traduzir por temperança e que implicava um perfeito domínio de si, aliando sabedoria e ação avisada. Para alcançar tal ideal, os gregos propõem um programa de estudos que inclui a ginástica, para o aperfeiçoamento físico, e a música, a leitura e o canto das obras dos grandes poetas, para o espiritual. Tratase de um programa ordenado por um ideal de equilíbrio e harmonia; um ideal de medida, de desenvolvimento equilibrado de corpo e espírito. É este ideal de kalokagathia que os latinos plasmam na fórmula "Mens sana in corpore sano." Fonte: http://www.educ.fc.ul.pt/docentes/opombo/hfe/protagoras2/links/paideia.htm.

7 Dentre os aspectos está a questão patriarcal da educação que privilegiava a educação dos meninos para serem cidadãos, negando o mesmo para as meninas.
} 
Acreditamos como Eisner que a arte deva ser mais considerada na educação, possibilitando-a novos ares, novas formas de fazer. Não por uma nostalgia, nem como revanchismo à ciência, mas como princípios educacionais que considerem o humano, o indeterminado, o que se constrói no processo de fazê-lo e que abarque sensibilidades. As artes podem ensinar aos estudantes a inventarem, a agirem e jugarem na ausência de regras, a perceber as sutilezas, a ter empatia, alteridade, a avaliarem atitudes e consequências, revisarem suas escolhas e projetarem soluções éticas. "Existe uma unicidade na experiência estética; um pensar na própria ação, presente em processos educativos" (MARTINS, 2011, p. 312). Artistas são adaptáveis aos processos que elaboram, desenvolvem qualidades quando investigam ideias, materiais, metáforas, quando ressignificam o trivial. Reconhecem a vida do caminho e alcançam uma adequação em ação, o que Dewey chamou de "propósito flexível" (Dewey, 2010). O professor que não adapta o plano no curso de uma aula, não está na "presença" de seus alunos, está alienado no plano. "E Dewey nos diz que, enquanto a ciência afirma o significado, as artes expressam significado. O significado não está limitado ao que é afirmado" (EISNER, 2008, p. 12). A arte pode ser uma grande sacada para uma educação desconectada com os interesses e desejos dos estudantes.

Os contornos dessa nova visão foram influenciados pelas ideias de Sir Herbert Read, um historiador de arte inglês, poeta e pacifista que trabalhou em meados do século passado. Ele argumentou, e eu concordo, que o objetivo da educação deveria ser concebido como a preparação de artistas. Pelo termo artista, nem ele nem eu necessariamente queremos dizer pintores e dançarinos, poetas e dramaturgos. Queremos dizer indivíduos que desenvolveram as ideias, as sensibilidades, as habilidades e a imaginação para criar um trabalho que seja bem proporcionado, executado com habilidade e imaginativo, independentemente do domínio em que um indivíduo trabalha. O maior elogio que podemos conferir a alguém é dizer que ele é um artista, seja como carpinteiro ou cirurgião, cozinheiro ou engenheiro, físico ou professor. As belas artes não têm monopólio sobre o artístico (EISNER, 2008, p. 09).

Neste sentido, é preciso voltar a pensar a docência como uma forma de arte inventiva no sentido foucaultiano e imaginativa como o trabalho do artista, e o artista como docente pode valer-se de suas particularidades para a invenção de uma aula como acontecimento participativo. Embora os currículos e os sistemas estejam sufocados pelo tecnicismo, "o segredo do mestre é saber reconhecer a distância entre a matéria ensinada e o sujeito a instruir, a distância, também, entre aprender e compreender. $\mathrm{O}$ explicador é aquele que impõe e abole a distância" (RANClÉRE, 2010, p.21).

Para Barrie Barrel (1991), Eisner propõe que o ato de ensinar se aproxime da arte, ou "que ensinar é uma arte", nesta acepção percebemos que o sentido que estes autores dão para a arte no processo de ensino se assemelha ao entendimento comum de arte como habilidade, nossa proposta está no sentido de que o processo de ensino seja uma forma de arte. Mas, ainda tendo essa leitura, Barrel nos traz importantes considerações sobre a abordagem artística da aula. 


\begin{abstract}
Ensinando como arte. Eisner argumenta que o ensino é uma arte baseada em quatro sentidos. Primeiro, ele afirma que o ensino pode ser realizado com tal habilidade e graça que tanto o professor quanto o aluno sentem que a experiência pode ser considerada justificadamente estética. Em segundo lugar, "ensinar é uma arte no sentido de que professores, como pintores, compositores, atrizes e dançarinos, fazem julgamentos amplamente baseados em qualidades que se desdobram durante o curso da ação". Terceiro, o ensino é uma arte, porque não precisa ser dominado por rotinas e maneiras prescritas de fazer as coisas. Os professores devem ter que trabalhar de maneiras inovadoras para lidar com uma variedade de contingências e eventos imprevisíveis que ocorrem no curso de sua instrução. Em quarto lugar, o ensino é uma arte no sentido de que os fins alcançados são frequentemente criados durante o processo de ensino. "O ensino é uma forma de ação humana em que muitos dos fins alcançados são emergentes - isto é, encontrados no curso de interação com os alunos, em vez de preconcebidos e eficientemente alcançado" (BARREL, 1991, p. 335). (TRADUÇÃO NOSSA)
\end{abstract}

Para concluir, estamos cientes de que é necessário se colocar em jogo ${ }^{8} \mathrm{com}$ os coletivos de estudantes e desenvolver uma relação menos institucionalizada. Embora ocupemos espaços institucionais que não compreendam o modus da arte: sua imprevisibilidade, seu processo caótico e não linear, sua necessidade em criar dissonâncias que coloquem em risco o status quo. Não podemos negar que esta também é uma das necessidades da arte, mudar o valor das coisas, questionar as instituições. E o professor flerta com o indeterminado, com a criação de uma aula como acontecimento participativo, com a ativação de corpos e de processos de criação. Ativando a rede onde os indivíduos, os coletivos e as instituições se conectem, ativando a experiência em comunidade onde todos aprendem de modo integral.

\title{
Referências
}

AGUIRRE, Imanol. Imaginando um Futuro para a Educação Artística. In: MARTINS, R.; TOURINHO, I. Educação na cultura visual: narrativas de ensino e pesquisa. Santa Maria: UFSM, p. 157-186, 2009. Disponível em: https://pt.scribd.com/document/60824348/Imaginandoum-futuro-para-a-educacao-artistica-Imanol-Aguirre . Acesso em: 07/02/2021.

ANDRÉ, Carminda M. Teatro Pós-dramático na escola. São Paulo: Editora UNESP, 2011.

BARREL, Barry. Classroom Artistry. In: The Educational Forum. n.55, p. 333-342, 1991. Disponível em: https://www.tandfonline.com/doi/ abs/10.1080/00131729109335665?journalCode=utef20 Acesso em: 07/02/2021.

8 Se colocar em jogo no sentido de se colocar fora da zona de conforto, pois este é o lugar da invenção. 
DE CERTEAU, Michel. A invenção do cotidiano: artes de fazer. Petrópolis: Ed. Vozes, 1998. DELEUZE, Gilles; GUATTARI, Felix. O que é filosofia? São Paulo: Ed. 34, 1992.

DEWEY, John. Arte como experiência. São Paulo: Martins Fontes, 2010.

EISNER, Elliot. O que pode a educação aprender com as artes. In: Currículo sem Fronteiras, v.8, n.2, p.5-17, Jul/Dez 2008. Disponível em: http://www.curriculosemfronteiras.org/artigos. htm Acessado em: 07/02/2021.

FAVARETO, Celso. É isso arte? São Paulo: Entrevista ao Itaú Cultural, 1999. Disponível em: https://www.youtube.com/watch?v=-XG-71wqwUI Acessado em: 06/02/2021.

FLEITH, Denise S. Criatividade: Novos Conceitos e Ideias, Aplicabilidade à Educação. Santa Maria: Revista Educação Especial, n 17,p. 55-61, 2001. Disponível em: https://periodicos. ufsm.br/educacaoespecial/article/view/5229 Acesso em: 05/02/2021

FOUCAULT, Michel. A verdade e as formas jurídicas. Rio de Janeiro: Nau Editora, 2002.

GIELEN, Pascal; Criatividade e outros fundamentalismos. São Paulo: Anablume, 2015.

KASTRUP, Virginia. Entre o encontro e a provocação: a ação mediadora. In: MARTINS, Mirian C; SCHULTZE, Ana M; EGAS, Olga. Mediando [con]tatos com arte e cultura. São Paulo, v.1, n.1, p.41-43, nov.2007.

MARTINS, Miriam C; DEMARCHI, Rita. Mediação cultural: entres sujeitos/corpos/ experiências estéticas. In: Revista Digital Art\&. São Paulo, AnoXIII, n. 17, Julho 2016. Disponível em: https://www.academia.edu/30965522/MEDIA\%C3\%87\%C3\%83O_CULTURAL_ENTRES_ SUJEITOS_CORPOS_EXPERI\%C3\%8ANCIAS_EST\%C3\%89TICAS Acesso em: 07/02/2021.

MARTINS, Miriam C. (Org). Mediação: Provocações Estéticas. São Paulo, Instituto de Artes, Pós-Graduação, volume 1, número 1, p. 1 -144, outubro 2005.

Arte, só na aula de arte? Educação, Porto Alegre, v. 34, n. 3, p. 311-316, set./ dez. 2011.

NIETZSCHE, Friedrich. Sobre a verdade e mentira no sentido extramoral. São Paulo: Ed. Hedra, 2007.

RANCIÈRE, Jacques. O mestre ignorante: cinco lições sobre a emancipação intelectual. Belo Horizonte: Autêntica, 2010.

RENZULLI, Joseph S. A general theory for the development of creative productivity through the pursuit of ideal acts of learning. Gifted Child Quarterly, 1992.

Submissão: 23/02/21

Aceitação: 05/04/21 